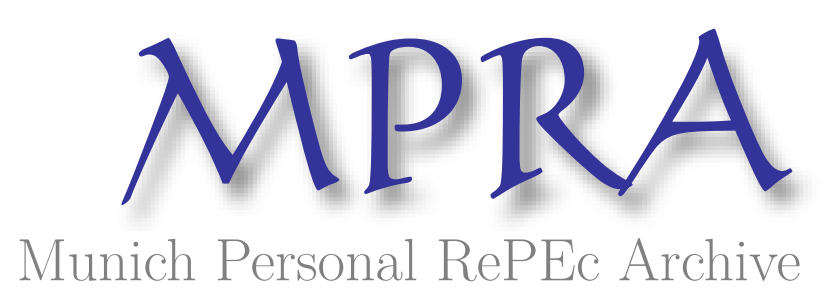

\title{
Standards and Agricultural Trade in Asia
}

Giovannucci, Daniele and Purcell, Timothy

ADB Institute

2008

Online at https://mpra.ub.uni-muenchen.de/13550/

MPRA Paper No. 13550, posted 22 Feb 2009 07:04 UTC 


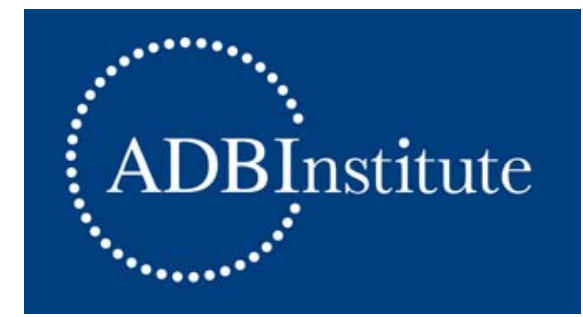

Standards and Agricultural Trade in Asia

Daniele Giovannucci

Timothy Purcell

May 2008

ADB Institute Discussion Paper No. 107 
Daniele Giovannucci and Timothy Purcell are consultants on agricultural trade standards and policy. See www.dgiovannucci.net or t.purcell@ agriculturaldevelopment.org.

The views expressed in this paper are the views of the authors and do not necessarily reflect the views or policies of $A D B I$, the Asian Development Bank (ADB), its Board of Directors, or the governments they represent. ADBI does not guarantee the accuracy of the data included in this paper and accepts no responsibility for any consequences of their use. Terminology used may not necessarily be consistent with ADB official terms.

ADBl's discussion papers reflect initial ideas on a topic, and are posted online for discussion. $A D B I$ encourages readers to post their comments on the main page for each discussion paper (given in the citation below). Some discussion papers may develop into research papers or other forms of publication.

This discussion paper is part of an $A D B I$ research project on contract farming and market facilitation for the rural poor. The project will produce a book, tentatively titled Making Globalization Work for the Poor and the Environment: Contract Farming and Organics.

Suggested citation:

Giovannucci. Daniele, and Timothy Purcell. 2008. Standards and Agricultural Trade in Asia. ADBI Discussion Paper 107. Tokyo: Asian Development Bank Institute. Available: http://www.adbi.org/discussion-paper/2008/05/22/2542.standards.agricultural.trade.asia/

Asian Development Bank Institute

Kasumigaseki Building 8F

3-2-5 Kasumigaseki, Chiyoda-ku

Tokyo 100-6008, Japan

Tel: $\quad+81-3-3593-5500$

Fax: $\quad+81-3-3593-5571$

URL: $\quad$ www.adbi.org

E-mail: info@adbi.org

(C) 2008 Asian Development Bank Institute 


\begin{abstract}
In developing countries markets for agri-food products are changing at a pace that is unparalleled in modern history. Markets are increasingly open and increasingly homogenized toward international tastes and requirements for levels of quality, packaging, safety, and even process attributes such as socially or environmentally friendly methods. New distribution channels, dominated by larger firms including supermarket retailers, are imposing high performance demands on their value chains. In order to respond to these increasing market demands, developing countries are facing an inexorable shift toward more industrialized models of farming systems. This shift represents new challenges for small and medium farmers' access to markets and their ability to compete, as traditional standards are often no longer adequate even in some of the more lucrative national or internal markets. The key for many is to understand and achieve new levels of standards.
\end{abstract}

The question for many countries-and not just developing countries-is what options are there for small farmers, which still comprise the great majority of the world's agricultural producers? Policy solutions will require a commitment to innovative institutional structures that can equitably link international capacity to local needs. A better understanding and collaboration with value chains via practical structures such as contract farming will help to ensure competitiveness and inclusion of small and medium-sized enterprises and smaller farmers.

JEL Classification: F12, Q12, D02, Q27 


\section{Contents}

I. Introduction 1

II. New Developments Affect Agricultural Producers' Market Access $\quad$ N

Global Developments Driving New Trade Processes 2

Standards Increasingly Set the Rules of the Game 3

Governance

Producers and SMEs Face Difficult Hurdles $\quad 6$

The Growth of New Distribution Channels 6

III. Overview of Standards and their Role in Market Access 9

Standards: Public and Private $\quad 9$

WTO Access and the Role of SPS and TBT Agreements 13

$\begin{array}{ll}\text { Harmonizing Standards } & 14\end{array}$

IV. The Current Capacity to Meet Emerging Market Requirements $\quad 14$

$\begin{array}{ll}\text { The Challenge } & 14\end{array}$

$\begin{array}{lr}\text { Inadequate Standards and Forsaken Value } & 16\end{array}$

$\begin{array}{ll}\text { Implications for Producers } & 17\end{array}$

V. Costs and Benefits of Agricultural Trade Standards and the Role of Contracts 18

Benefits: Direct and Indirect 19

Costs: Direct and Indirect $\quad 20$

$\begin{array}{ll}\text { The Role of Contracts in Agricultural Trade Standards } & 21\end{array}$

$\begin{array}{ll}\text { VI. Conclusions and Recommendations } & 22\end{array}$

$\begin{array}{ll}\text { Synthesis } & 22\end{array}$

Policy Focus 23

Policies 23

Public and Private Roles $\quad 24$

$\begin{array}{ll}\text { References } & 27\end{array}$ 


\section{INTRODUCTION}

In developing countries, the markets for agrifood products are changing at a pace that is unparalleled in modern history, becoming increasingly open and homogenized toward international standards. New distribution channels, dominated by larger firms, are imposing higher performance demands, including social and environmental standards, throughout the value chains. Traditional ways of doing business are often no longer adequate, resulting in new challenges for small and medium farms. Acquiring the technical know-how and financial resources to incorporate standards such as quality assurance, safety, and traceability is difficult and failure to do so marginalizes many small and medium farms and agroenterprises.

The public institutions that could traditionally provide such support to farmers have steadily eroded and are now often non-existent. Until the late 1980s, rural development was typically state-focused, with public institutions controlling the systems and infrastructure for agrimarket inputs and outputs. These institutions were, for the most part, unceremoniously scrapped as their shortcomings became evident, free-market theories became prominent, and structural adjustment took hold. Their role in supporting smaller, more marginalized or remote producers, however, was important in facilitating equitable access to information and markets. Consequently, their absence in poorer regions has exacerbated market failures and left a vacuum that is not often adequately filled by the private sector.

Through the lenses of value chain theory and institutional economics, we are beginning to better understand the interrelationship of private sector agricultural production and trade with the emerging processes of civil governance. From such understanding can emerge the necessary innovation and support required to provide sustainable solutions to the challenges of necessary capacity building or long-term financing required by smaller farmers and rural entrepreneurs who want to participate in the value chain. Without effective public and civic institutions, the ability of smaller farms and enterprises to participate is reduced.

\section{NEW DEVELOPMENTS AFFECT AGRICULTURAL PRODUCERS' MARKET ACCESS}

Due to improved logistics, faster communication, and fewer trade barriers, markets are increasingly open as well as increasingly homogenized toward international standards. Large farming systems are incorporating greater skills and more investment in technology and infrastructure to enable more controlled and large-scale production that is difficult for smaller farmers to achieve. The new market access challenges faced by smaller farmers do not apply just to exports since national or internal markets are beginning to imitate international standards, as part of a shift in the structure of distribution channels away from small local markets toward, for example, supermarkets.

Supermarkets typically procure steady supply and large volumes of products from suppliers. For small farms, to enter into a supermarket's procurement system may require heavy capital and technological investment as well as a more skilled labor force. Agricultural standards play an important role in these procurement systems. Often, farmers simply cannot meet these standards on their own (Reardon and Berdegué 2002ab). Arrangements such as contract farming are one way to resolve the uneven relationships between many small suppliers and a few large buyers.

Agricultural standards evolved over the course of many years and were in essence codified publicly by regular accepted use, but the last decade or so has seen dramatic changes. New and often private standards are demanded by buyers in order to meet their value chain management needs or to reduce their exposure to risk. 
How standards drive developments in the global agrifood system is intimately linked with functions of governance within the value chain; that is, conditions for participation in the chain are set, implemented, monitored, and enforced. In the past, these rules mainly dealt with meeting basic cost parameters and guaranteeing supply. However, as outlined by Giovannucci and Reardon (2000), standards have now become tools for product differentiation, playing new roles as strategic tools that are used for market penetration, safety assurance, traceability, quality control, incorporation of social and environmental guidelines, and even the definition of product niches.

Smallholders in the supply chain often lack the internal capacity and the economies of scale to establish effective quality assurance and traceability systems. Small enterprises and producers, especially sectors that are export-dependent, may be marginalized unless they can make standard compliance cost effective and guarantee traceability for the buyers.

\section{Global Developments Driving New Trade Processes}

Today, because there is great exposure and public risks when standards fail to maintain food safety or when they permit social and environmental harm, they are driving a number of new processes such as Hazard Analysis at Critical Control Points (HACCP) and sustainability standards such as organics. The globalization of these value chains and the enormous volumes and concentrations of buying power can mean dramatic consequences for thousands or even millions of people. Recent scares, like mad cow disease, avian flu, or E. coli, have demonstrated how the failure of standards can cripple an entire subsector, even across developed nations such as the US and UK. As a result, not only firms but also governments and consumers are increasingly concerned.

This concern is being progressively translated as higher requirements for market entry, including food safety, traceability, higher quality, and even certifications of process, i.e., HACCP, ethical, Fair Trade, organic, etc. These requirements are being driven by changes in three major areas:

\section{A new consumer environment}

Characterized by a predominant interest in personal health and increasing doubt in the ability of government to ensure food safety, this includes broader concerns such as unchecked chemical use in livestock that has led to antibiotic resistance in humans. ${ }^{1}$ Increased transparency and communications has led to more information and greater concern about the social and environmental conditions in the place of origin.

\section{A new business environment}

In the agrifood business, an increasing concentration of suppliers, intermediaries, and retailers stimulates new methods of differentiation and spur a more intense drive for new supply sources and greater efficiencies in costs and logistics. As global corporations face new risks, they adopt various risk management techniques, especially the demand for more standards. Fulponi (2005) notes that setting standards above minimum levels and requiring third-party certification and traceability are a corporate response to the risk of civil or criminal responsibility. These risks are not only based on food safety but also concerns for labor violations such as those reported in some cacao production regions, worker safety in flower

\footnotetext{
${ }^{1}$ One of the world's most prominent medical associations warned of the dire human health consequences of the increasing resistance to antibiotics in the US where only 12 percent of all antibiotics are used for humans and the remaining 88 percent are routinely fed in intensive livestock operations (New England Journal of Medicine, 1999). That journal has also noted that a likely result is that antibiotic-resistant infections had increased 800 percent between 1992 and 1997. Some countries have banned the routine prophylactic use on livestock, and Denmark, for example, saw its antibiotic resistance drop from 82 percent to 12 percent (Robbins, 2003).
} 
industries and fish packing plants, and below-subsistence wages in the coffee industry. In recent years, a record number of leading global companies voluntarily reported on social and environmental issues within their firms (Global Corporate Responsibility Reporting Trends 2006). Many used independent audits to help ensure their transparency and credibility.

\section{A new regulatory environment}

As more and more food is traded globally, all governments struggle to monitor and manage the safety of their food supplies, typically by imposing new barriers to entry in the form of public standards, including import bans to manage a variety of livestock diseases or stiffer border inspections for contamination and phytosanitary violations. In some cases, governments resort to regulations such as the US bioterrorism laws and the EU's Maximum Residue Levels or GMO restrictions.

These three environments have combined to stimulate the evolution of numerous standards. As public standards have multiplied, so have those mandated by private industry. Since 1995, more private international food-related standards have emerged than in the previous five decades combined. Clearly, standards have become an important competitive factor and are becoming an important determinant of access to markets.

\section{Standards Increasingly Set the Rules of the Game}

Standards offer quality and safety assurance as well as differentiate and define product categories. In addition to food safety, taste, cosmetic quality, and nutritional value, they increasingly involve process requirements such as environmental impact, worker health and safety, animal welfare, and fairness to primary producers. In some cases, suppliers are required to provide reasonable assurance of social and environmental benefits that range from an International Organization for Standardization (ISO) series to HACCP to Organics. Such requirements can either facilitate market penetration or act as barriers to entry. Accordingly, standards are the new rules and they are evolving dynamically. Indeed, a common argument for private standards is that firms believe they can more quickly respond to market needs by controlling their own standards. Understanding and meeting them is becoming increasingly challenging.

As incomes grow, so does the tendency to consume perishable foods such as meat, dairy, and aquatic products that are more susceptible to conveying life-threatening diseases. This tendency may be fueled by greater communication and trade influencing consumption patterns to resemble those of US and European consumers, whose tastes have been toward greater consumption of meat and dairy products where food safety standards are critical. Concomitantly, governments have become more sensitive to agriculture safety as scares ranging from BSE to avian flu impact human health and wreak economic havoc in some regions. $^{2}$

These shifts mean more pressure on producers and processors to comply, and many enterprises are simply not prepared. In the People's Republic of China (PRC)-where the majority of processors are small and medium enterprises (SME) - the total number of processors has shrunk by two-thirds in the past decade as food processing has shifted from traditional, lower-risk products to meat, dairy, and aquatic products and horticultural produce that require higher standards and greater investments (see Figure 1).

\footnotetext{
${ }^{2}$ For example, outbreaks of avian influenza in Southeast Asia during 2004 and 2005 halted the production and trade in poultry products, affected suppliers of feed and other inputs, severely reduced tourism, and seriously affected other parts of the economy, not least of all the deaths of some 204 people up to November 2007. Estimates of the economic loss are around 1.5 percent of the GDP for some of those affected countries.
} 


\section{Figure 1: Output Structure in Chinese Food-processing Industries, Percentage of Total 1998-2003}

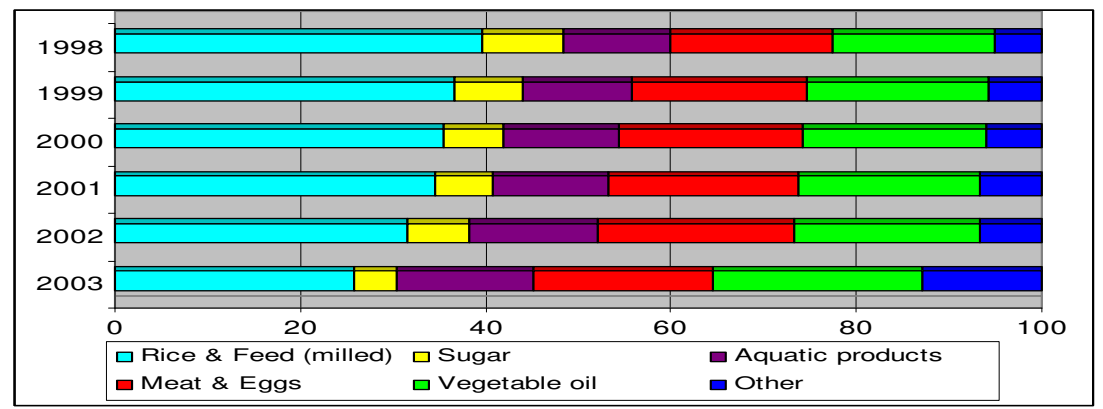

Source: Adapted from data of Chinese Food Industries Year Book, 1999-2004 in Lu (2005).

A report released by Rabobank predicts that the PRC will become the world's third-largest fresh produce exporter within three years. ${ }^{3}$ Despite ongoing difficulties with meeting some standards in advanced markets, the PRC is forging ahead with high-value exports and has invested in standards and control systems to manage this output. It already produces half of the world's fruit and vegetables, mostly for domestic consumption, and exports of these products reached US\$7.2 billion in 2006. According to FAOSTAT, this represents a substantial $7 \%$ of global trade in fruit and vegetables and trails only the Netherlands, the US, and Spain. ${ }^{4}$

Experience from other regions already points to some difficulties. Jaffee and Henson (2004) note that the rejection of agricultural imports due to not meeting standards cost low- and middle-income countries about US\$1.6 billion in 2000-2001. In 2002, the PRC, Thailand, Turkey, Brazil, and Viet Nam accounted for nearly $60 \%$ of the EU's rejections from non-EU sources (Jaffee and Henson, 2004). USDA and FDA statistics note a rising trend in such food safety problems, with reports almost doubling from 1994 to 2004 (Center for Science in the Public Interest, 2007), and these US agencies plan to advocate preventive controls, including higher import safety standards.

\section{Governance}

Standards take different forms. They may be set in commercial legal codes and subject to fines if transgressed, they may be internationally recognized and widely used even though they have no specific legal basis, or they may be private, firm-specific requirements (see Table 1).

Standards can be enforced by participants within the chain as well as by external agencies. From within the chain, the key sanction is excluding a supplier from participating. The converse of this is that well-performing suppliers can be favored with longer-term contracts and higher prices (Kaplinsky and Morris, 2001). Sanctions may also be exercised outside the chain, and many governments have extensive bureaucracies checking compliance with legislation and even prosecuting offenders. In recent years, NGOs have grown into an important sanctioning force. Boycotts and publicity campaigns, or the threat of them, have also forced many leading firms to change the way they produce or to delist particular suppliers (Kaplinsky and Morris, 2001).

\footnotetext{
${ }^{3}$ Cited in "China inching up world exporter list." Accessed September 2007: http://www.freshinfo.com/index. php?s=n\&ss=nd\&sid=40288\&s_txt=Patrick+Vizzone+China\&s_date=0\&ms=7.5261569023132\&offset=

${ }^{4}$ The Netherlands figure is skewed by considerable trans-shipments through its ports, and Spain's is heavily dependent on a few citrus crops.
} 
Table 1: Characterizing Different Types of Standards

\begin{tabular}{|l|l|l|l|l|l|}
\hline \multicolumn{2}{|l|}{ Type of Codification } & Legal Codification & $\begin{array}{l}\text { Internationally } \\
\text { Agreed }\end{array}$ & $\begin{array}{l}\text { Regionally } \\
\text { Specific }\end{array}$ & $\begin{array}{l}\text { Firm } \\
\text { Specific }\end{array}$ \\
\hline \multirow{3}{*}{$\begin{array}{l}\text { Type of } \\
\text { standard }\end{array}$} & Product & $\begin{array}{l}\text { - Food hygiene } \\
\text { standards }\end{array}$ & $\begin{array}{l}\text { - Codex Alimentarius } \\
\text { - Grades of wheat } \\
\text { - Moisture level for } \\
\text { coffee beans }\end{array}$ & $\begin{array}{l}\text {-EU MRLs } \\
\text {-EU GMO limits }\end{array}$ & $\begin{array}{l}\text { Chiquita } \\
\text { residue and } \\
\text { size } \\
\text { standards }\end{array}$ \\
\cline { 2 - 6 } & Process & $\begin{array}{l}\text { - Workplace } \\
\text { health and safety } \\
\text { standards }\end{array}$ & $\begin{array}{l}\text {-ISO9000 (quality) } \\
\text {-SA8000 (labor) } \\
\text { - Fair Trade }\end{array}$ & $\begin{array}{l}\text {-BRC } \\
\text {-ASEAN-GAP }\end{array}$ & $\begin{array}{l}\text { Starbucks } \\
\text { sourcing } \\
\text { practices }\end{array}$ \\
\hline
\end{tabular}

Source: Adapted with changes and additions from Kaplinsky and Morris (2001).

What is common to value chains is the increasing concentration of power among a few actors, leading to increased horizontal and vertical coordination. The considerable purchasing power of large-scale retailers in particular, enables them to set private standards that are typically diverse, can be confusing, and are always more demanding than the public safety standards of most countries. Since standards can be influenced considerably by both public and private sectors, producers and processors of agricultural products have to serve many masters.

The world's largest grocery retail markets by value are now the USA, Japan, the PRC, India, and the UK, and by 2020 the PRC is expected to more than double its value and move into second place. All these markets share development characteristics defined by the nature of their distribution channels. Today's retail food industry increasingly resembles the definition of a classic oligopolistic industry. At the top are large multi-unit retailers that tend to dominate consumer food distribution in many countries. For example, in the US the top five supermarket chains accounted for over $40 \%$ of retail food sales in 2000, while in 1993 they accounted for $20 \%$. In France during this same period, the top five chains increased market share from 48 to $61 \%$ while in Italy it more than doubled from 11 to $25 \%$ (Busch and Bain, 2004).

The largest are powerful multinationals and include US-based Wal-Mart with more than 5,000 mostly hypermarket-type stores, France-based Carrefour with more than 11,000 stores of varying formats, and Netherlands-based Royal Ahold with more than 5,000 supermarkets. As reference, their annual revenue is greater than the total value of any country's agriculture sector. Wal-Mart revenues, for example, topped $\$ 300$ billion, and its international sales exceeded $\$ 70$ billion in 2006. Such dominant players are the major drivers behind a staggering global flow of commodities, products, information, and finance that coordinate the activities of hundreds of millions of farmers and affect billions of consumers. ${ }^{5}$

\footnotetext{
${ }^{5}$ As an example, in Europe while there are around 3.2 million farmers and 160 million consumers, there are in fact only 600 supermarket companies and 100 wholesale distributors supplying the majority of the markets (Grievink, 2003). While most of the major supermarket chains have their own integrated distributor systems, the smaller chains and independents rely on outsourcing their purchasing and distribution systems to independent wholesalers. In another example from Australia, three supermarkets (Woolworths, Coles, and Franklins) control nearly 80 of the grocery sales, and three wholesalers (Davids, Australian Independent Wholesalers, and Foodland Associated Limited) supply all retailers (COA, 1999). AIW, is a subsidiary of Woolworths. The concentration of buying power in a few companies means that it is very difficult for smallholder farmers from developing countries to gain access to such high-value markets.
} 


\section{Producers and SMEs Face Difficult Hurdles}

Developing country producers and SMEs face a number of hurdles to participate effectively in higher-value trade. An IFPRI article (Hazell, 2004) refers to the often-stated need for better infrastructure, linking to markets, and credit (among others) and notes that nonetheless, these still do not sufficiently address the problems of compliance with an increasingly complex standards environment.

Project effectiveness reviews for the countries of the Africa, Caribbean, and Pacific signatories of the Lomé Convention, looking at Quality \& Conformity in the Fruit \& Vegetables Subsectors, note that private standards present formidable technical barriers that have a negative effect on smallholders. Exporters select only the best-performing smallholders to be organized into groups, and these are expected to manage food safety and traceability systems. In addition to the high cost of certification, there is evidence that weaker farmers are often excluded. For example, one of Zambia's largest horticulture exporters limits itself to source only one product from smallholder producers. ${ }^{6}$ The exporter fears that if the smallholder cooperative cannot meet the required standards, it may risk losing its Global-GAP certification.

Institutional structures are necessary to achieve a form of vertical coordination that can overcome transactions costs and standards barriers that smallholders face. In the Philippines, as in other countries, the growing popularity of contract hog farming allows feed millers to use smallholders' labor and land, and to fatten hogs at low cost. Such small-scale livestock operations have thrived in many regional markets. As that changes, and largescale industrial operations become ever more dominant, small enterprises without the support of institutional structures and organizations are less likely to survive.

\section{The Growth of New Distribution Channels}

Recent studies point to the shift in marketing channels available to producers and the rapid rise of supermarkets in developing countries (Reardon, 2005; Bingen and Busch, 2005; Fulponi, 2005; Reardon et al., 2003; Moustier et al., 2005). The 1990s saw the emergence of supermarkets as a major form of retailing in many developing countries (see Box 1), becoming dominant players in many Latin American countries with the trend moving rapidly in East and Southeast Asia and more slowly in South Asia (see Figure 2). This development is substantially transforming the nature and the composition of domestic agrifood commerce as well as regional and overseas trade.

\section{Box 1: Supermarkets Emerge in US and Explode in Latin America and Asia}

Developments around the supermarket concept are representative of trends experienced in other multi-store retail formats. The supermarket-self-serve, larger scale retailer often with more than one check-out counteremerged in the US about 75 years ago.

Between 1925 and 1955 supermarkets captured more than half of US grocery sales. By the 1980s they had become the dominant food distribution channel in the US. Today Germany, the UK, and France show supermarket shares of food retail at $70-80 \%$. This business model, now refined, has emerged much more quickly than that of either the EU or the US, with strong implications for domestic and regional food suppliers.

\footnotetext{
${ }^{6}$ The exporter only contracts for baby corn, a product that is less likely to result in pesticide residues.
} 
Figure 2: Growth in Supermarkets on a Regional Basis, 1997-2002

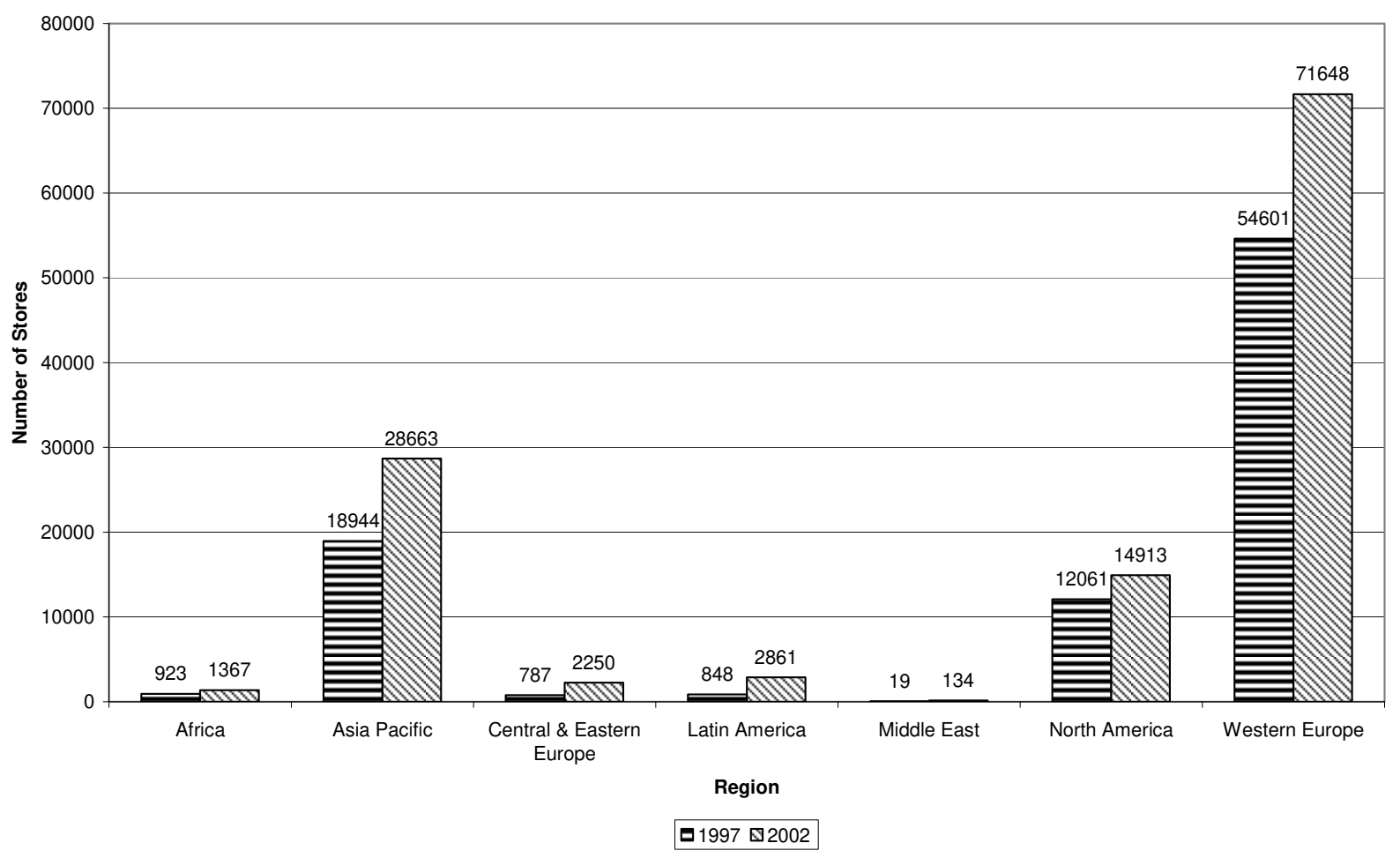

Source: M+M Planet Retail

It is important to understand the effects of this market transformation, not only on producers and value chains but also on the entire agrifood system, since it affects costs and distributional issues from the farm to the table. Within these larger trends, several important developments can be observed:

- Increasing demands for higher levels of farmer performance in quality, process, and financial capacity to invest in technology and operating capital;

- Greater centralization of retail procurement with the advent of the specialized, sophisticated multi-country logistics management wholesaler replacing traditional wholesalers;

- Greater use of contracts and private systems to identify and reward preferred suppliers.

The Asia region now represents barely a third of all of the global food retail sales. It is forecast to grow to $41 \%$ of the global food retail market by 2020 while Europe will comprise $30 \%$ and the NAFTA area will shrink to $21 \%$ (IGD calculations). Multiple store retailers will be an important part of that as they are growing fast throughout the world, particularly with the liberalization of emerging markets and Foreign Direct Investment (FDI). These include small-scale convenience stores, such as those associated with gasoline stations, supermarkets, and full-service retailers such as hypermarkets. 
Developing countries are not exempt from the trend toward supermarkets. South America, parts of Europe, and advancing East Asian economies saw their supermarket share of food retail grow from about $10-20 \%$ in the early 1990 s to more than $50 \%$ just a decade later (Reardon and Berdegue, 2002). The supermarket sector in Asia is now growing even faster than in Latin America (Reardon et al., 2003). The authors, citing A.C. Nielsen statistics, note that supermarkets in East Asian countries, such as those in the Republic of Korea; Taipei,China; and the Philippines, have achieved an average $63 \%$ share of the food retail in those countries (excluding the fresh segment, i.e., meat, fish, fruits, and vegetables). In Southeast Asian countries such as Thailand, Indonesia, and Malaysia, supermarkets have already captured an average 33\% share of the non-fresh food retail. Applying the calculations of Reardon and others in Latin America, one can estimate that supermarkets' share of the fresh segment in Asia is approximately half of their total share in packaged foods.

In some countries the growth has been even more rapid. Indonesia's supermarkets' share of food retail was negligible before 1998 and by 2005 reached about $30 \%$ of the total (Natawidjaja et al., 2006). In the PRC, where supermarkets did not exist prior to 1990, they controlled $13 \%$ of total food sales by 2003 , approximating the situation in Brazil and Argentina in the early 1990s but with one difference: the PRC is registering growth that is three times greater than Latin American growth rates in the 1990s. According to $\mathrm{Hu}$ et al. (2004), supermarkets in the PRC are growing faster than in any other nation at 30-40\% per year. By 2002, supermarket sales in the PRC had already reached $\$ 55$ billion, up from $\$ 10$ billion in 1996. Strong growth is likely to continue. IGD predicts that the entire Chinese grocery market will grow by $65 \%$ to US $\$ 456$ billion between 2005 and 2010 .

The dominance of these new retail formats has resulted in the emergence of demanding new procurement channels and the decline of smaller informal markets that could more readily accept both small quantities and inconsistent qualities of foods from farmers and middlemen. In Viet Nam and the PRC, as supermarkets develop fast in cities, government policies favor centralization of food distribution and the reduction of street vending and informal markets (Moustier et al., 2005; Reardon, 2005). ${ }^{7}$

The demands in the domestic markets of less developed nations are growing and are increasingly resembling those of export channels. Latin America, for example, is a primary exporter of fruits and vegetables, yet over the last 15 years supermarkets have grown to sell about 3 times more fruits and vegetables than are exported from the region. Reardon et al. (2005) and Vander Stichele et al. (2006) also claim that the increasing market domination by big corporations and multinational supermarket chains influences the prices producers receive and the conditions under which they must produce. The consolidation of procurement implies great challenges for smaller producers. ${ }^{8}$

Supermarket channels have demanding private standards similar to export requirements for size, color, safety, consistency, volume, packaging, labels, etc., which implies the need for production level investments in drip irrigation, greenhouses, advanced storage, hygienic

\footnotetext{
${ }^{7}$ In Viet Nam, for example, the Domestic Trade Department of Hanoi views some street vendors as an undesirable influx of the rural and peri-urban poor coming into the city on a daily basis to sell products on the street, causing congestion, unsightliness, and a waste management problem.

${ }^{8}$ The increasing use of standards and contract systems in the global retailing industry has the potential to restrict access of smallholder producers to these higher-valued chains. In Bangladesh, as an example, Agora Supermarkets only had two branches in 2004. In order to obtain fresh produce they had contracting relationships with thousands of smallholder vegetable growers. They had planned to open two additional branches in 2005, and then to stop purchasing much of their food locally (within Bangladesh) and instead source everything from overseas. With four branches they believed they would then have enough volume of sales to enable them to order by the container load directly from Singapore (sourced from Australia, New Zealand, and the US). Ultimately, it was easier to deal with one freight forwarder in Singapore than thousands of farmers (Purcell and Hassanullah, 2004).
} 
services, and logistics. These effects served to consolidate the many small suppliers to Thailand's largest supermarket chain, so that only the more professional operators-usually organized groups or larger farmers-could continue to trade with it directly (van Roekel et al., 2001).

More investment and operating capital are also needed since the greater volume of export and supermarket channels often means lower margins and delayed payments from buyers. Meanwhile, the traditional middlemen and general wholesalers that provided the framework for moving products from farms to processors and retailers are morphing toward specialized procurers for larger retailers and chains. Consequently, spot and wholesale markets tend to decline in importance and forward contracts expand (Reardon et al., 2003). These contracts often involve requirements for much larger and more sophisticated harvest and storage operations, centralized distribution systems, and longer shipping distances that create an increasing need for clear standards.

\section{OVERVIEW OF STANDARDS AND THEIR ROLE IN MARKET ACCESS}

Thousands of standards or standards-related agreements exist for the agrifood sector. While many are public with common applications, most of today's agricultural trade standards are privately set by groups or firms and apply primarily to their specific needs. The complex distinctions between process and product characteristics and different types of indirect costs associated with standards can dramatically diminish their benefits and effectively make them barriers to entry (Giovannucci and Ponte, 2005). Standards affect not only producers but also value chains, agribusinesses, and consumers, so it is vital to understand who is forming standards, their motivations, their increasing privatization, and the impacts.

\section{Standards: Public and Private}

Public standards revolving around food safety, consumer protection, and trade facilitation are embodied primarily in government regulations and some international codes and accords. The public standards of individual governments are also important. Often they are the primary portal that products must pass through, and they can be both rigorous and mandatory.

Private standards are those imposed by buyers and usually require higher levels of performance than the baseline public standards. These can apply to such areas as quality, process management, packaging requirements, or social concerns. While public standards are typically clear and well established, private standards can be more difficult, particularly because they can be fast-changing. Though sometimes called voluntary, private standards are becoming the basic de facto entry requirement for trade with many of the large-scale operators and leading value chains.

Meeting private standards is becoming essential for doing business in higher-value agriculture. Among the best-known private standards are those of the International Standardization Organization (ISO) series, HACCP, Fair Trade, Organic, and Good Agricultural Practices (GAP) adopted by entities such as EUREP or ASEAN. Sometimes private sector standards like Certified Organic or HACCP are adopted and codified by government as regulations.

In addition to the private standards noted above, individual firms are also developing their own internal norms that may differ from the current broader sectoral norms. Firms ranging from Cargill and Unilever to Cadbury, Starbucks, and Nestle all have undertaken such efforts. 
Process standards are typically private in character and typically refer to the entire cultivation, packaging, or manufacturing process. These serve as criteria for sourcing decisions, and some pay closer attention to the responsible use of agrochemical inputs, energy, water, wastes, and the impact on communities and the environment. In addition to well-known process standards such as GAP, GMP, HACCP, and ISO, the cause-related standards are becoming increasingly popular. Some better-known examples are:

1. Organic

2. Fair Trade

3. Ethical Trading Initiative

4. Rainforest Alliance

5. SA-8000

6. UTZ Certified

These are sometimes referred to as sustainability standards and are unique in that they can embody somewhat intangible social and environmental characteristics; see Error! Reference source not found.. Although all are managed by or originate from NGOs, these standards have evolved to become much more public in their objectives, transparency, and standard setting. All are nonprofit, ${ }^{9}$ and it can be argued that they fulfill a public good while filling a growing consumer demand.

\section{Organic}

Organic is the fastest-growing sector of the food industry, with global sales doubling since 2001 and exceeding US $\$ 40$ billion in $2007 .{ }^{10}$ High market growth rates are leading to supply shortages in some sectors such as fresh produce, meat, dairy, and certain processing ingredients. The Asia region alone has experienced triple-digit growth in organic farmland between 2000 and 2006. The International Federation of Organic Agriculture Movements (IFOAM) is the global coordinating body for Organics.

Organic standards are among the most misunderstood. They are sometimes considered to be simply the absence of synthetic inputs; however, this is only one aspect of an organic system. Organic agriculture relies on scientific and traditional knowledge to work with biological and mechanical methods to manage ecological systems. It works to optimize quality and sustainability while reducing external inputs and synthetic materials.

Social issues such as labor rights and conditions are also part of organic principles but not commonly part of certification requirements. General environmental principles are clearly embedded in organic principles, but specific guidelines on aspects such as biodiversity are not necessarily part of the certification processes. Organic certification can also apply to processed food, and in this case most artificial preservatives or additives are avoided.

For the purposes of most trade, organic products are third-party certified and include both internal controls and traceability. However, for local applications, different credence mechanisms are often utilized that do not depend on formal certification processes. These are often lower in cost and can be equally effective (Giovannucci, 2005).

Table 2: Comparative Overview of Some Popular Process or Sustainability Standards

\begin{tabular}{|l|l|l|l|}
\hline Feature & Organic & Fair Trade & Rainforest Alliance \\
\hline Premium & Premium likely paid & Premium assured & Modest premium often \\
\hline
\end{tabular}

\footnotetext{
${ }^{9}$ In some countries organic standards have become public standards by virtue of laws that regulate their application.

${ }^{10}$ Calculation based on historic growth data reported by IFOAM and Organic Monitor
} 


\begin{tabular}{|c|c|c|c|}
\hline & $\begin{array}{l}\text { especially if certified - but not } \\
\text { assured }\end{array}$ & & paid but not assured \\
\hline $\begin{array}{l}\text { Yield and } \\
\text { quality }\end{array}$ & $\begin{array}{l}\text { Short-term impact on yields } \\
\text { may be negative; possibly } \\
\text { positive impact on some } \\
\text { aspects of quality }\end{array}$ & $\begin{array}{l}\text { Only indirect (and } \\
\text { possibly positive) impact } \\
\text { of yields and quality due } \\
\text { to higher income for } \\
\text { inputs and labor }\end{array}$ & $\begin{array}{l}\text { Potentially negative } \\
\text { yield impact; possibly } \\
\text { positive impact on } \\
\text { some aspects of } \\
\text { quality }\end{array}$ \\
\hline $\begin{array}{l}\text { Other income } \\
\text { impacts }\end{array}$ & $\begin{array}{l}\text { Possibility of selling other } \\
\text { organic products from the } \\
\text { certified farm; income } \\
\text { diversification }\end{array}$ & $\begin{array}{l}\text { Group collaboration } \\
\text { facilitates economies of } \\
\text { scale }\end{array}$ & $\begin{array}{l}\text { Possibility of selling } \\
\text { forest as well as } \\
\text { agricultural products }\end{array}$ \\
\hline Market access & $\begin{array}{l}\text { Access to well-established } \\
\text { and reliable market }\end{array}$ & $\begin{array}{l}\text { Access to small but well- } \\
\text { established market }\end{array}$ & $\begin{array}{l}\text { Buyers and markets } \\
\text { limited but increasing } \\
\text { fast with major brands }\end{array}$ \\
\hline $\begin{array}{l}\text { Extension, } \\
\text { credit }\end{array}$ & $\begin{array}{l}\text { Possible extension from } \\
\text { supportive NGOs but limited } \\
\text { support from public system }\end{array}$ & $\begin{array}{l}\text { Improved access to trade } \\
\text { financing and credit and } \\
\text { improved financial } \\
\text { position of cooperatives }\end{array}$ & $\begin{array}{l}\text { Possible agro-forestry } \\
\text { extension from } \\
\text { supportive NGOs, but } \\
\text { limited support from } \\
\text { public system }\end{array}$ \\
\hline $\begin{array}{l}\text { Social impact } \\
\text { and } \\
\text { organizational } \\
\text { capacity }\end{array}$ & $\begin{array}{l}\text { Potential increase in mutual } \\
\text { support among farmers to } \\
\text { solve farming management } \\
\text { problems }\end{array}$ & $\begin{array}{l}\text { Increased organizational } \\
\text { capacity of participating } \\
\text { farmers; access to } \\
\text { training; community } \\
\text { projects }\end{array}$ & Through social norms \\
\hline $\begin{array}{l}\text { Environmental } \\
\text { impact }\end{array}$ & $\begin{array}{l}\text { Improved soil fertility as well } \\
\text { as resistance to drought and } \\
\text { erosion; no synthetic } \\
\text { agrochemicals }\end{array}$ & $\begin{array}{l}\text { Limited environmental } \\
\text { benefits }\end{array}$ & $\begin{array}{l}\text { Improved biodiversity } \\
\text { and agro-ecological } \\
\text { conditions }\end{array}$ \\
\hline $\begin{array}{l}\text { Risk, planning } \\
\text { capabilities }\end{array}$ & $\begin{array}{l}\text { Risk reduction through } \\
\text { reduced external inputs; no } \\
\text { mono-cropping; soil } \\
\text { resilience }\end{array}$ & $\begin{array}{l}\text { Cooperative level } \\
\text { planning; guaranteed } \\
\text { price reduces risk }\end{array}$ & $\begin{array}{l}\text { Integrated pest } \\
\text { management }\end{array}$ \\
\hline
\end{tabular}

Source: Adapted with modifications from Giovannucci and Ponte (2005).

\section{Eco-friendly or Safe Foods}

A broad range of standards exists that are focused primarily on ecological systems and the assurance of agricultural products produced in a manner that avoids toxic chemicals or other forms of contamination. Rainforest Alliance standards are among the best known of this category and are sourced in dozens of countries for sale primarily to the US, Europe, and Japan. Some nations have also developed standards. Japan has a government production standard that references ecologically friendly measures as well as food safety and requires certification by an accredited body. In the PRC "Green Foods" are government-certified products are labeled under government supervision as safe from chemical contamination with their production and processing using more environmentally friendly processes. This standard is recognized only in the PRC, but some trading partners in Japan and Europe have accepted it as a substitute assurance for basic food safety measures. In 2003, green food exports topped US $\$ 1.5$ billion. Other governments including Malaysia and Thailand have developed certifiable standards for agriculture. In India, less formal approaches include several traditional holistic farming systems based on ancient techniques for soil and animal management that eschew synthetic inputs and are in harmony with natural on-farm inputs and cycles. These are neither government regulated nor formally certified but are followed in many of the country's regions and are commonly called either "Jaivic Krishi" or "Vedic Krishi." 


\section{Fair Trade}

Fair Trade is an alternative to the often asymmetrical buyer/producer negotiations featured in conventional trade and aims to improve the livelihoods and well-being of small producers by assuring a fair price agreement, continuity in trading relationships, and the strengthening of small-producer organizations. Fair Trade products are typically sold in more developed markets via an NGO-operated certification system. Fairtrade Labelling Organizations International (FLO) is the global coordinating body for certified products. Nearly 60 countries now export a variety of certified Fair Trade products and they are sold in more than 50 countries. In 2006, the estimated retail value in these markets was more than $€ 1.6$ billion and products were sourced from two dozen developing countries. ${ }^{11}$

\section{Codex}

Codex Alimentarius is an intergovernmental body facilitated by the UN's Food and Agriculture Organization (FAO) and the World Health Organization (WHO) that aims to protect consumer health and facilitate international trade in food. For decades its guidelines have been internationally recognized benchmarks for food products and form a basis for many standards, including national standards and those recommended by the World Trade Organization (WTO). For example, it has evaluated hundreds of food additives and common contaminants and set maximum residue limits for approximately 2,500 combinations of commodities and pesticides.

While certainly beneficial, particularly in setting baseline public standards and the development of many national regulations, ${ }^{12}$ Codex is a large, consensus-oriented organism and is therefore relatively slow to adapt to the needs of day-to-day trade and recommend timely changes.

\section{ISO}

The ISO is a network of national standards institutes from 157 countries and is organized as an NGO. Within its objective to facilitate international exchange of goods and services, it sets a number of the most popular trade standards and fosters standardization activities. Its standards are voluntary and typically codify sectoral best practices. Although ISO certification does not refer to the output of the process but only that a process is in place, it is perceived as a signal of conscientious management.

An increasing number of ISO's 15,000 standards and guidelines are relevant to producers and agrifood enterprises. The 9000 series, the most popular, promotes good management practices to ensure the consistent quality and delivery of goods and services. The 14000 series promotes sound environmental management in order to minimize negative effect caused by various productive activities including agricultural processing.

ISO is increasingly writing overview standards that capture trends in agrifood trade, such as ISO 22000, which is designed for generic food safety, ${ }^{13}$ and the forthcoming ISO 26000 , which covers voluntary guidance on social responsibility and is slated for publication in 2010. ISO's importance extends to verification mechanisms in that many governments and private

\footnotetext{
${ }^{11}$ Based on FLO data, November 2007.

${ }^{12}$ Cambodia has adopted all of the Codex standards-at least on paper. Viet Nam had adopted about $60 \%$ of Codex standards relating to food and foodstuffs as of 2005 and planned to adopt all remaining ones (MOT and EU, 2005).

${ }^{13}$ ISO 22000 is an auditable standard and aligned with Codex's HACCP but goes farther with requirements for food safety management systems and specific areas such as strengthening prerequisite programs and transforming the recommendations into requirements. ISO 22000 is coming into use, and the US Seafood Inspection Program (National Marine Fisheries Service) will soon start to audit for compliance with both ISO 9001 and ISO 22000
} 
firms insist that certification bodies comply with a standard (ISO65) that is an international equivalent and recognized for other rulings such as European Norm EN 45011. ${ }^{14}$

\section{HACCP}

Hazard Analysis at Critical Control Points (HACCP) is a systematic analysis for potential food safety risks within, for example, a post-harvest or processing operation. The analysis typically identifies appropriate control and monitoring systems to minimize such risks. It assures that such a management approach has been established but not whether it is used or how effectively.

It is most often used with higher-risk foods, such as poultry, livestock, and fish products. Typically, HACCP reduces food contamination risk in two ways:

1. Anticipates potential problems or failures before they happen and does not depend only on a final inspection;

2. There is a greater likelihood of resolving the problem during process rather than at the end of the process or once the product moves into the supply chain or market.

Consequently, HACCP can also yield cost savings in terms of reduced waste, reprocessing, or recalls.

\section{GAP and GMP}

The more recent ASEAN GAP standard is adapted to Asia-Pacific conditions and has many similarities to EUREP-GAP (known as Global-GAP as of September 2007). These standards are widely used by many companies, especially by firms that export to Europe. They are based on Good Agricultural Practices (GAP) that promote basic food safety principles to minimize biological, chemical, and physical hazards associated with crops from seed through harvest storage. ${ }^{15}$

Good Manufacturing Practices (GMP) begin from the harvest and storage stage and serve to guide the people working in contact with food, its packaging materials, and work environs to conform to basic sanitation and hygiene practices to protect against food contamination from both direct or indirect sources. These standards also typically improve worker safety.

\section{WTO Access and the Role of SPS and TBT Agreements}

The public or governmental application of sanitary and phytosanitary (SPS) or technical measures can act as standards and have a growing impact on the nature and direction of international trade controls. Although part of the WTO for some time, the SPS and Technical Barriers to Trade (TBT) agreements are increasingly important ways to manage trade in light of the diminution of tariffs, quotas, and other formal measures. For example, Environmental and Related Health Requirements-provisions for which are contained in both the SPS and TBT agreements-have nearly doubled (rising from 10\% to 18\%) as a percentage of WTO notifications since the early 1990s (UNCTAD, 2006).

SPS measures are intended to ensure human food safety and protect agricultural plant and animal populations and ecosystems. Each country sets food safety and animal and plant

\footnotetext{
${ }^{14}$ Similarly, ISO 61 is the recognized guideline for accreditation bodies and is often the benchmark for national rulings on this (e.g., The European EN 45010). ISO 62 covers quality system certifiers.

15 They specifically address the following topics: site selection; adjacent land use; water; fertilizers; herbicides/pesticides; hygiene; field, facility, and worker hygiene; product cooling; and transportation.
} 
health standards based on its own assessment of acceptable risk levels. The SPS agreement recognizes the right of countries to maintain national standards that are stricter than international levels, although they must be justified by scientific evidence and should be consistently applied.

The TBT agreement aims to stop WTO members from using arbitrary technical regulations, standards, or testing and certification procedures to protect domestic producers. It applies to all aspects of food standards not covered by the SPS agreement, including labeling requirements, nutrition claims, and quality and packaging regulations, which are generally not considered as either sanitary or phytosanitary measures. TBT prevents members from distinguishing between goods on the basis of either production or processing methods but specifies conditions when members may restrict trade using technical regulations or standards.

The WTO recognizes three organizations as sources of internationally agreed-upon benchmark agrifood standards that can affect SPS and TBT: the Codex Alimentarius, the Office International des Epizooties (known as OIE) for animal health, and the International Plant Protection Convention (IPPC) for plant health. The OIE is an 83-year-old intergovernmental organization that analyzes and disseminates veterinary information to provide expertise and transparency in control of global animal disease (includes aquatic). The IPPC is a standards treaty that aggregates 19 approved international standards, establishing measures to prevent the introduction and spread of plant pathogens and pests. Its Secretariat is within FAO, but it works through National and Regional Plant Protection Organizations such as the Asia and Pacific Plant Protection Commission or the European and Mediterranean Plant Protection Organization to help countries meet their IPPC obligations.

\section{Harmonizing Standards}

Efforts have been made to develop more coherent meta-standards, particularly for food safety. Theoretically at least, they would permit the rapid movement of foods from country to country and facilitate the learning process of producers and processors when they are meeting only one general standard. Understandably, these efforts would raise issues of domestic impact in each country, particularly in poorer nations. The International Committee of Food Retail Chains (CIES) Global Food Safety Initiative is one harmonization effort to provide a single set of rules for standards. The International Social and Environmental Accreditation and Labeling (ISEAL) organization also strives to achieve harmonization among some of the most important eco-social standards bodies including IFOAM, Rainforest Alliance, FLO, UTZ Certified, and the Forest Stewardship Council. Their efforts can provide useful stepping stones for countries to collectively adopt standards guidelines and training

frameworks that have broad-scale relevance and can reduce the individual cost of compliance.

\section{THE CURRENT CAPACITY TO MEET EMERGING MARKET REQUIREMENTS}

\section{The Challenge}

Standards are difficult for many developing-country farmers to achieve, yet they provide unique market opportunities. By meeting certain standards, farmers can reduce the risk of rejection in the marketplace as well as access new, more profitable market segments. Since standards set some producers apart, the differentiation they represent serves as a competitive tool. Clearly, SMEs and smaller farms in developing countries face challenges in meeting them. Many struggle to learn and apply these new expectations, and evidence is building that if they cannot achieve at least basic standards they risk being excluded from competitive markets both regionally and internationally with potentially serious 
consequences for economic growth, poverty alleviation, and even food security (Vander Stichele et al., 2006; Moustier et al., 2005; Reardon et al., 2003). Most producers face common barriers when considering standards:

1. Selecting which among the standards requires a good measure of market intelligence and contact with buyers as well as experience in assessing the relative demands, costs, and benefits of each-something for which there is almost no data whatsoever;

2. Few institutions exist to facilitate the adoption of standards as an ongoing learning process that takes both time and consistent training;

3. Capital to invest in new processes, equipment, and infrastructure is difficult to access;

4. Transaction costs for certifying products can be high and a barrier to entry;

5. Risky learning is often done at an international level since local market demand is modest.

Many processors, exporters, and retailers-especially for higher-value products-favor producers that can meet their demands for standards, large volumes, and year-round consistency. They sometimes create their own collection or purchasing systems that bypass local market networks thus reducing access. Typically this forces small- and medium-sized suppliers to either consolidate into organizations or larger firms or to compete for the lowervalue channels that remain. Three quick-sketch case studies point to the positive and negative experiences of different approaches; see Box 2, Box 3, Box 4.

\section{Box 2: Thailand Case Study}

A value chain analysis was carried out on Tops Supermarket group, a dominant food retailer in Thailand. The study noted:

- Variability of prices due to high losses from inadequate storage and refrigerated transport.

- Slow order response time from poor production methods, planning, and information flow.

- Inability to meet product specifications because of inadequate quality controls.

- Coordination difficulties among small suppliers.

- Lack of trust and cooperation among participants in the value chain.

Tops Supermarket had a number of specific requirements for perishables that were not being met by its existing supply structure. When Tops insisted that its suppliers be certified under the Ministry of Agriculture's new food safety program, most were unable to comply, and 190 of the 250 current suppliers were eliminated (Boselie, 2002). Most smallholders had difficulties meeting the conditions so only a few could continue and only by organizing as a group of second- or third-tier suppliers and subcontracting to the larger preferred suppliers that had the capacity and could afford the investments necessary to directly contract with World Fresh Distribution Center (van Roekel et al., 2001).

This case demonstrates that competitive requirements served to eliminate smaller-scale participants. In this instance, public-private cooperation led to overcoming the problems for some of the more able participants. However, the lack of appropriate institutional structure and the explicit intent to integrate a broader group of suppliers effectively led to the exclusion of many.

\section{Box 3: People's Republic of China Case Study}

Under different organizational models small producers have demonstrated a notable ability to meet very high quality standards and even achieve international certification. In the towns of the Feicheng area of the PRC's Shandong Province, local government committees have provided the institutional framework to organize large-scale value chains that feed processing companies in the region. Several companies are involved, and one of these, the Tai'an Asia Food Co., is a Sino-Japanese joint venture that receives the production of approximately 10,600 farmers. Farmers typically earn several hundred 
US dollars annually, a remarkable sum considering that their average farm size is less than 0.1 ha.

Feicheng specializes in high-value organic produce for overseas markets and is somewhat unique in that much of it is reclaimed land that was rendered toxic from excessive chemical use. The area produces 20 kinds of internationally certified horticulture crops with annual production volume of approximately 130,000 tons.

With government acting as a catalyst, the processors, local input, transport, training enterprises, and farm communities have developed relations reminiscent of Porter's cluster model. ${ }^{16}$ The interface between farmers and the large enterprises is often mediated by local government, which provides a tailored framework to support the farmers' participation. It involves training, certification, extension services, and the facilitating of input distribution where necessary.

The critical lessons derived here revolved around having access to sufficient and consistent training, especially during the conversion phase when many producers were unfamiliar with the new requirements. A steadfast, reliable institutional structure, e.g., local government, facilitated the producers' willingness to adopt new methods and substantially reduced their risk. Equally important was the presence of a dependable value chain that ensured access to lucrative markets.

Source: Original case study conducted for Giovannucci (2005).

\section{Box 4: Indonesia Case Study}

For most Indonesian consumers, fresh fruit and vegetables (FFV) are taking on an increasing share of their total food expenses. This is especially true in urban areas where supermarket channels are capturing an increasingly greater share of the business, but much of the business does not involve Indonesian producers.

Natawidjaja et al. (2006) found that nearly all retailers prefer to purchase imported FFV products rather than deal with Indonesian farmers due to inadequate value chains, missing or low-quality infrastructure, and poor standards. A striking $60 \%$ of the FFV sold by supermarkets are imported (approximately $80 \%$ of the fruit and $20 \%$ of the vegetables). This is considerably higher than the figure in other comparable developing countries. Larger retailers source directly from large-scale importers, while specialized wholesalers are making inroads by focusing on supplying the demanding needs of modern food industry channels such as fast-food chains and restaurants, institutional users, and supermarkets.

In West Java, the most prolific FFV production area, farmers typically lack capital and selforganization to produce according to requirements of supermarkets. Some specialized or dedicated wholesalers are increasingly working with small farmers but not more than $15 \%$ in any area.

The notable lack of support services and institutional and physical infrastructure leads wholesalers and farmers to perceive the new FFV markets as a very difficult challenge met only by the most capitalized and capable. This makes most Indonesian FFV farmers essentially uncompetitive in their domestic consumer markets.

\section{Inadequate Standards and Forsaken Value}

Lu (2005) estimates that in 2004 alone the PRC experienced approximately $\$ 8$ billion in reduced exports due to its failure to meet standards in numerous agricultural subsectors. This has happened in almost every sector, including grains, apiculture products, livestock, fungi, and fruits and vegetables. For example, the prohibition of Chinese animal products to the EU in 2002 caused a $\$ 623$ million loss for 94 Chinese food-processing enterprises. In 2002 and 2003, the PRC's export value of frozen spinach to Japan decreased by $\$ 372$ million compared to that of two years prior due to rejections for agrochemical residues. Even the US faced problems with standards when an E.coli outbreak leading to three deaths in

\footnotetext{
${ }^{16}$ Michael Porter's cluster theory is useful for understanding the nature of complementary and sometimes competitive enterprises grouping in a region for mutual benefit. See, for example, Porter (1980).
} 
mid-2006 resulted in expected losses for the US spinach industry ${ }^{17}$ reaching $\$ 100$ million for the year.

The recent discovery in Europe of illegal, genetically modified rice from the PRC prompted the European Commission to discuss far-reaching import restrictions that would affect numerous rice farmers. This would apply also to non-GMO farmers from affected areas, in effect burdening them for the standards compliance failure of their compatriots. It is not just the inability to meet food safety standards that diminishes potential income. Coffee producers in Cambodia and Laos, lacking technology and processing infrastructure, often cannot meet the basic quality requirements of international markets, and their production is now limited to domestic markets and some proximate cross-border trade.

Similarly, Viet Nam's prodigious coffee trade is second to rice as the largest agricultural export earner and directly employs 600,000 workers. Much of the production quality, however, is such that its exports have consistently earned less per pound FOB than any of the top ten producers between 1993 and 2003 (ICO statistics).

The EU is Bangladesh's most important client for its fourth-leading export: frozen shrimp and fish. In 1997 the EU banned Bangladeshi fishery products due to inspections that found serious infrastructure and hygiene deficiencies in processing establishments and insufficient quality control guarantees by government inspectors. Cato and Subasinge (2003) note that, in just five months that year, the revenues lost (US\$15 million) nearly equaled the investment required to upgrade those plants and train personnel (US\$18 million). The impact, both reputational and monetary, on the industry and economy of Bangladesh was substantial.

\section{Implications for Producers}

Currently, increased standards primarily impact those dealing with larger buyers or with the market for higher-value products. The developments in several countries noted previously indicate this will eventually be part of the equation for more buyers and for a broader range of products, even in secondary markets. Opportunities exist to better understand and adapt to new standards requirements in the secondary and regional markets in order to be better prepared for the eventual growing demands of those markets as well as to export competitively to the most lucrative markets.

For producers to be competitive and have market access, they have to address eight development areas:

1. Institutional structures - to deliver localized production training and farm and organizational management;

2. Market intelligence - understanding what to produce, at what time, and according to what standards in order to meet buyer specifications;

3. Quality - better inputs, particularly high-quality seed and appropriate varietals, for market-oriented production and capital investment for harvest and post-harvest requirements;

4. Quantity - group organization for smaller producers to aggregate the necessary volumes;

\footnotetext{
${ }^{17}$ http://www.cnn.com/2006/US/10/26/spinach.fears.ap/index.html
} 
5. Consistent supply - appropriate late- and early-season varietals as well as investment in greenhouse production;

6. Trade transactions - sound contract law that is accessible with simple dispute resolution mechanisms;

7. Certification - low-cost certification and efficient product testing services;

8. Trade financing - contract farming and other internal value chain financing are important but will likely be insufficient.

Enforcing standards without adequate incentives is difficult. IFAD research evaluating organics in Asia (Giovannucci, 2005) found that some aspects of standards may be bypassed where producers gain little benefit from compliance, especially where compliance is not easily checked at the farm gate. In the case of arabica coffee, Varangis et al. (2003) found that where farmer production was blended together by traders, thereby losing individual product identification, there was little or no reward for compliance or higher-quality and minimal penalty for non-compliance. Accordingly, the overall quality suffered as few farmers complied with the established standards.

\section{COSTS AND BENEFITS OF AGRICULTURAL TRADE STANDARDS AND THE ROLE OF CONTRACTS}

Clearly, standards are a risk management tool, particularly for buyers that want to ensure the quality and safety of their supply. The demand for standards is being pushed increasingly upstream in value chains toward producers as a result both of government initiatives and private sector demands. When producers or processors can meet the required standards, they naturally improve their market access. In some cases producers may also enjoy other direct benefits and costs.

Benefits:

- Improvement in operational and managerial efficiency;

- Greater participation in global supply chain and high-value products;

- Environmental benefits of erosion reduction and soil improvement;

- Health benefits;

- Food security, including that of the rural poor (small farmers);

- Economic benefit: price premiums.

Costs:

- Transition difficulties potentially affecting yields;

- Investments in time and learning;

- Financial investment for infrastructure and technology;

- Higher operating costs for more complex processes. 


\section{Benefits: Direct and Indirect}

In some cases, implementing standards can improve operational and managerial efficiency. For example, the requirement to keep good records of farm inputs and their application can facilitate internal costs and benefits analysis and improve future planning. Giovannucci in Asia (2005) and Damiani in Latin America (2003) found that when small-scale traditional producers shifted to organic standards, they incurred additional costs but generally enjoyed long-term yield improvements and profitability due primarily to better farm management practices and price premiums. The results among intensive producers were mixed, with some resulting in net economic benefits and others resulting in few, if any, economic benefits (Giovannucci, 2005; Giovannucci, 2006).

Some standards - particularly those that require independent certification-intrinsically fulfill many of the broader requirements for producers to participate in global supply chains or compete in high-value products. For example, detailed recordkeeping of production inputs, traceability, and third-party monitoring that are part of organics are also useful to improve chain competitiveness and more effectively participate in lucrative markets.

Sustainability-oriented standards appear to have some additional benefits for farmers. For example, several recommend diversification away from dependence on a single cash crop, thereby reducing a producer's risk of crop failure. Pretty et al. (2005) reviewed 286 agricultural project interventions in 57 poor countries and noted that the application of improved environmental standards (IPM, organics, LEISA, ${ }^{18}$ etc.) not only generally improved the supply of critical environmental services for the communities but also increased productivity on most of the 12.6 million farms covered. Several standards including GAP offer environmental benefits; studies have shown that these can reduce erosion and improve soil quality (FAO, 2002; Mader et al., 2002).

Food security is of particular concern in areas of rural poverty. By fostering agricultural methods that improve not only the soil's natural fertility but also its ability to withstand natural calamities such as drought (Altieri, 1999; Drinkwater, Wagoner, and Sarrantonio, 1998) and more efficiently use nutrients (Mäder et al., 2002), the likelihood of food shortages can be reduced. Setboonsarng (2006) notes several studies showing farmers that meet organic standards enjoy a number of advantages. For example, lower production costs can improve farm viability while diversification reduces the likelihood of catastrophic crop failure, and ecological management of local resources further contributes to local food security.

Increasingly, sustainability concerns are emerging in many private standards such as Global-GAP and ISO. These may have some reference to the considerations of Organic, Fair Trade, or eco-friendly approaches while remaining simpler and less demanding. In most cases, meeting standards such as Organics means producers are able to meet the environmental requirements of many, though not necessarily all, other standards.. Bartram and Perkins (2003) reviewed 33 published studies and concluded that substantial biodiversity advantages existed when organic standards were applied. The field-to-table traceability, animal management requirements, and restrictions on the use of agrochemicals provide reasonable assurances of increased farmer safety, food safety, and animal health. The importance of farm-level diversification and a price premium for the required processes and certification further help to ensure a measure of economic benefit.

Besides the clear economic value of market access, the evidence for direct economic returns resulting from the application of standards is less clear. In many cases, meeting a standard is not associated with a higher or premium price; it is simply a requirement for doing business in any high-value product. In commodities and lower-value products, the

${ }^{18}$ Low External Input Sustainable Agriculture 
failure to meet standards is likely to result in a lower price. This is the case for most GAP or GMP standards and all food safety standards. The research on the actual costs and benefits incurred in the adoption of standards is rather limited, although some attempts are currently being undertaken, the foremost being the Committee on Sustainability Assessment (COSA) measuring both direct and indirect costs and benefits of the major sustainability standards at not only the economic level, but the social and environmental levels as well. ${ }^{19}$

It is hard to tell the extent to which a price premium is paid for achieving a standard or for meeting a quality level since many products also have some physical or organoleptic quality requirements and the reasons for payment are often not distinguished. In some cases a price premium is clearly associated with the achievement and maintenance of a particular certification; this happens most often with the more complex and demanding process standards related to sustainability such as Organic and Fair Trade.

For products that are Fair Trade certified, typically a minimum price agreement exists that is considered a fair living wage for the producer. Organic product certifications can require considerable transition costs, recordkeeping, and traceability that elicit a price premium. Similarly, eco-friendly standards such as Rainforest Alliance's are seen as an opportunity cost for producers electing to maintain biodiversity and environmental integrity; these too usually command a price premium. UTZ Certified currently commands a very modest premium though it is too early to tell if that will change for this fast-growing standard as it covers new crops beyond coffee. Ethical trade standards employed in several countries have resulted in improved market access but no clear indication of consistent market premiums. Conversely, when products fail to meet basic standards, they are likely to face a price penalty.

\section{Costs: Direct and Indirect}

Several types of costs typically are involved in the adoption of standards. First, a learning curve can require a large and prolonged time investment. This can also require sometimes costly institutional support from a producer organization, community, government agent, or NGO. Confusion about the types of standards and their specific requirements is an intangible cost. Little research has been conducted on these costs. Second, investment is sometimes required in equipment or infrastructure to meet standards. Third, the need for independent verification or certification for compliance and traceability also involves an expense. Traceability through the chain is increasingly relevant and challenging particularly in critical situations, e.g., positive residue tests, false or fraudulent declarations, or discrepancies in quantities traded. While direct certification costs are relatively simple to measure, it is difficult to categorize other typical costs of adopting standards since they depend heavily on two broad-ranging variables: the requirements of a specific standard and the producer's or processor's current ability to meet that standard.

Adopting some standards involves a relatively modest change. In other cases, the transition can take years and a prolonged investment before costs are recouped. Without reliable market access, the often-higher operating costs of a new standard can be onerous.

Standards are not necessarily exclusionary for small producers. Some that are oriented toward sustainability can sometimes provide an advantage for smaller producers. The typically more localized and labor-intensive aspect of organic standards mostly lend themselves better to smallholders. Fair Trade standards are designed specifically for small producers and laborers.

\footnotetext{
${ }^{19}$ www.iisd.org/standards/cosa.asp
} 
Standards can have unintended consequences-and considerable costs-for producers as well as entire agricultural subsectors. For example, the lack of credible public food safety standards in Bangladesh caused the poultry products market to drop by $75 \%$ for nearly a year after bird flu was found in Southeast Asia even though not a single case was reported in Bangladesh.

Standards can impose unexpected and unremunerated costs at the local level. In Southeast Asian banana plantations, Dardaine (2003) notes that buyers insist that workers wear gloves and masks while spraying at the packing station where temperatures can reach $40^{\circ} \mathrm{C}$ yet will not increase the price paid for a box of bananas to cover such costs. Some emerging coffee standards piloted by some of the world's largest coffee companies to improve sustainable field practices present an interesting case study. The International Coffee Organization (2004) noted that such standards risk becoming a barrier to entry since they impose requirements that producers themselves have to finance in order to participate. The embedded environmental and social practices may be useful and improve farm management, but when imposed on smaller farms without the capital or skills to affect the changes, they can negatively impact the very sustainability that they propose to support.

A number of nations have guidelines and laws for the growing or importation of genetically modified organisms (GMOs), and these present a unique challenge. Unlike a standard that can be met gradually or eventually, GMO contamination of non-GMO crops may be more permanent and is not something that producers can readily alter. The potential for genetic drift is causing trade problems for some producers and countries such as the US and Canada when after industry assurances of containment capability, a number of food crops and storage facilities were discovered to contain GMOs. The EU has already imposed systematic order inspections in August 2006 as an emergency measure after the discovery of illegal, genetically modified rice from the PRC.

Standards can provide opportunities for increasing sustainable production and improving quality and overall competitiveness. The application of standards, however, is a difficult adjustment for many farmers faced with reduced extension services, inadequate information, and outdated capacities. The application of private grades and standards could inadvertently lead to the consolidation of producers, largely eliminating smallholders and the poor from the value chain. A number of countries are now supporting initiatives to develop largely privatesector-based tools such as contract farming to better deal with this challenge.

\section{The Role of Contracts in Agricultural Trade Standards}

Contract farming is a way to enable small and medium producers to access the benefits of standards. Using contractual arrangements, agro-industry can assist some farm families to shift from traditional agriculture to production of higher-value products (Patrick, 2003). This may potentially increase incomes of contracting smallholders, reduce risks, and have multiplier effects in the rural economy.

In the context of agriculture, Sykuta and Parcell (2002) explain that a contract codifies the rules of transactions through three key elements: value, risk, and decision rights. A successful contract allocates value, risk, and decisions in a way that is mutually beneficial, ideally sharing risk and improving quality and production (MMWBP, 2005). As such it can assign roles in meeting standards and other difficult demands of modern agrifood trading systems.

Generally the buyer selects standards and transmits this condition up the value chain. Small producers may be unfamiliar with the requirements of standards and unable to access the necessary technology or equipment. Then a contractor can more readily serve as a conduit for providing such requirements, and producers are relieved of finding the right product or 
technology and financing its initial purchase. Since producers rarely visit the terminal markets for their products, they may not be fully aware of specific requirements. In several southern African nations, one processing and exporting firm was able to enter a market dominated by European producers when it expanded its extension services to local farmers, using technology to help them understand and achieve the desired color range for peppers that were to be exported as paprika (van Gent, 2005; Giovannucci et al., 2001).

Contract farming can also improve market access especially for smaller producers. As contractors work with farmers to ensure that standards are met, they also aggregate supply and provide the necessary packaging, transportation, and transaction requirements to enable sales and higher-value markets. For example, a large commercial horticultural firm in Zambia helps smallholder farmers sell EUREPGAP certified vegetables to Europe by providing them access to the firm's own packing plant and airfreight quotas (Purcell and van Gent, 2005).

A certain balance of power between participants in the value-chain is necessary to facilitate sound relationships, and unless farms are quite large or well organized, this requires the presence of viable institutional structures. Poulton et al. (2004) noted in the case of Africa that contracts were more successful where there was neither monopsony buyer power nor perfect competition among buyers (MMWBP, 2005). As an example, in Viet Nam, contract farming of undifferentiated products such as ordinary rice has not succeeded as it has with specialty products such as organic aromatic rice, because side-selling is more difficult for specialty products (MMWBP, 2007).

In Viet Nam, the enactment of Decision 80 in 2002 attempted to increase the use of contracts to improve procurement and efficiency in the rural economy. The government has tried to provide incentives for parties to engage in contracts by providing favorable access to finance, land, and infrastructure. However, contracts under Decision 80 have largely been unsuccessful to date. Nguyen Do Anh Tuan et al. (2004) and Tran Cong Thang et al. (2004) suggest that three main issues have compromised such contracts. First, farmers have been accused of reneging on contracts when higher prices are offered from traders. Second, when buyers are faced with oversupplies of products from contracted producers, quality standards are sometimes tightened so processors can reject unwanted output. Third, knowledge of contractual obligations by parties in the contract is often lacking (MMWBP, 2005).

For contracts to be successfully used in many Asian countries, several areas will need to be improved. First, a "one size fits all" approach toward contracts may hurt, rather than help, producers and buyers. Second, the limited organization of producers and the imbalance in market relationships that are not addressed by institutions lead to failures. Third, greater knowledge is required in both the public and private sector to educate those engaged in contracts on the nature of contractual obligations and to develop enforcement mechanisms (formal or informal) that improve the governance of contracting relationships. Combined, these issues suggest both greater public sector roles and also greater strengthening and tightening of the value-chain through improved private-sector organization. Without such measures, the poor are unlikely to benefit from their participation in contracting relationships to raise quality and improve production practices (MMWBP, 2005).

\section{CONCLUSIONS AND RECOMMENDATIONS}

\section{Synthesis}

Standards are increasingly critical for global trade competitiveness and becoming more decisive at the domestic level in less developed countries. Trends indicate that even for domestic markets, standards will increasingly represent the rules of the game. This is 
especially true for higher-value and perishable products including fruit, vegetables, seafood, dairy, and meat products. Standards, like the markets they serve, are dynamic and rapidly evolving. They pose very substantial challenges, especially for smaller producers. Yet, within the challenge of standards there are a host of opportunities.

As Hoffman notes, ${ }^{20}$ governments should look beyond the immediate costs to the prospects and the catalytic role that standards offer both for national competitiveness and environmental sustainability. For developing countries, these standards provide competitive options with higher-value products, especially sustainability standards such as organics whose process management and traceability can aid market entry and whose application methods are well suited to small-farm conditions.

The public sectors in most developing countries often lack know-how in this area, and their capacity to provide extension services and marketing support has further diminished in recent decades. A measure of public support, often with private partnerships, i.e., contract farming, semi-private extension, etc., is vital to ensure efficient and affordable participation for small and medium farmers or rural enterprises. Given the unique nature of standards, an innovative response will be necessary in order for government to be effective. Two issues are predominant:

1. Information and capacity building to help producers, firms, and traders compete;

2. Institutional structures to enable the majority of farmers and SMEs to invest and participate.

\section{Policy Focus}

Van Gelder et al. (2006) note that "Policies on food safety often lead to standards that cannot be met by southern countries" and that a program to build capacity is necessary to meet standards. The World Bank, formulating its rural strategy in 2003, acknowledged how market trends require a new focus on knowledge, value chains, and sustainability that align with the inevitable standards needed for higher-value crops, sustainable production systems, and chains. This change in emphasis reflects a similar policy focus in many of its progressive client countries.

\section{Policies}

Policies play a big role, and particularly those that influence distributional outcomes will contribute to competitiveness in the long run as small and medium rural entrepreneurs develop and advance the sector. For example, for small and medium producers to participate in the livestock sector requires coordinated taxation policy between producers and their contractors. In this sector, inputs (primarily feed) can represent three-fourths of the cost of production (FAO), and many nations tax market transactions between the contractors (feed and input suppliers) and producers who raise the animals. In contrast, most nations do not tax the grain transfers within integrated operations. Taxing transactions with small producers not only is a relatively modest source of government revenue but also creates a disincentive for working with such out-growers, giving larger, vertically coordinated firms a distinct advantage.

It can be difficult to determine which standards to select for development training. Some standards are highly specific to a subsector or desired in a particular market. However,

\footnotetext{
${ }^{20}$ Ulrich Hoffmann, Chief, UNCTAD Trade and Sustainable Development Section, address to plenary conference on Trade and Environment Dimensions in the Food and Food Processing Industries in Asia and the Pacific (16-18 October 2006).
} 
numerous basic standards are relevant across both sectors and markets and are therefore the most useful starting points. For example, integrating GAP practices into basic production methods can provide a measure of basic production sustainability and also the baseline requirement for many other field standards. Subsequent interventions would likely progress toward more sophisticated standards such as organics that can have broader local environmental impacts and international market relevance

\section{Public and Private Roles}

Public and private roles around the issue of standards are intimately intertwined and complementary. At some levels the public sector is intrinsically too slow to be an effective arbiter or facilitator of the many increasingly important private standards. The private sector too has its limitations, primarily the failure to adequately address the public concerns for food safety and value chain equity. Still, some useful distinctions exist between private and public sector responses to changes in technical standards.

On the whole, the public sector in many developing countries appears unprepared to handle the new norms, since public formulation and enforcement of standards have been relatively weak or even absent. This is important since even the slow-to-change public standards, such as Minimum Residue Levels, are progressively more demanding. A clear concern exists about the possible use of public standards as a non-tariff trade barrier. Even if they can be met, the high compliance costs imply the possible erosion of the comparative production advantages in developing countries.

Private standards are often developed at the firm level. ${ }^{21}$ The expansion and proliferation of these standards can generate particularly onerous transaction costs for producers and SMEs. Small farms typically face higher compliance costs than larger ones as they are more likely to lack internal control systems, technical capacity, and investment capital. Therefore, if they do not either participate in proactive value chains or have a measure of institutional support, they may essentially end up producing less-tradeable goods.

Accordingly, dealing with standards requires new, more agile institutional frameworks than traditional methods. As such, innovative institutional structures can equitably link international capacity to local needs. A better collaboration with value chains via practical structures such as contract farming will help ensure competitiveness and inclusion of SMEs and smaller farmers. Consequently, it is imperative for government to take the lead in creating an enabling environment to meet three objectives:

1. Knowledge management infrastructure to both distill information and provide access to it;

2. Business development strategies that integrate with the private sector to ensure standards relevance;

3. Institutional structures oriented to producers but also encompassing the entire chain to guarantee both equity and long-term competitiveness.

The recent ubiquitousness of standards and new value-chain models present a unique opportunity to learn and develop appropriate interventions that spur the competitiveness of inputs, production, processing, and marketing.

\footnotetext{
${ }^{21}$ Trade associations also create standards in their role as proxies for private firms.
} 


\section{Knowledge management}

Knowledge management systems are vital to aid awareness and understanding of the drivers, threats, and opportunities implicit in the relevant and forthcoming standards. This includes dedicated, locally accessible knowledge platforms so that producers, SMEs, and value chains can better understand emerging market trends in different areas, differences between standards, and implications of adopting particular ones. For example, the work of the Sustainable Commodity Initiative's Committee on Sustainability Assessments (COSA) provides institutions with a detailed grasp of producers' full costs and benefits involved in adopting diverse sustainability standards and initiatives.

Although standards are dynamic and changing, their basic premises are consistent and can be conveyed in a variety of teaching forms, which range from farmer field schools to influencing the curricula of Technical and Vocational Training schools in order to enhance the skills of farmers and extension agents.

Although education can provide the basis of learning, producers and traders also need knowledge management systems that can provide progressive and more dynamic market intelligence. Market intelligence requires services that can assess the nature of demand, standards requirements, trends, and projections in the relevant markets. Rather than setting up new market information systems, it would be more productive to link with existing private sources of information that are increasingly available and also with ongoing public initiatives such as those developed by the International Food Policy Research Institute (IFPRI) and by the International Center for Tropical Agriculture (CIAT by its Spanish acronym).

\section{Business strategies}

It can be particularly productive for government to partner with the private sector in order to develop strategic medium- and long-term public responses that effectively support competitive value chains. The trade participation of most producers and SMEs will occur through value chains. These are characterized by systemic rather than individual efficiencies, and value chains both generate and distribute rents, though not necessarily equally. Without accessible knowledge systems and supporting institutions, smaller and weaker chain members are more likely to be eliminated than strengthened.

Public-private partnership can help smallholder producers to more effectively participate in value chains; yet, an important lesson on the public side is for government to adequately address the potential exclusionary impacts of standards development.

\section{Institutional structures}

While national-level reach is important, locally relevant institutional structures are vital in order to both create immediate local capacity and establish the institutional trajectories necessary to foster long-term agricultural competitiveness as well as include a broader portion of rural producers and SMEs.

These institutional structures and supporting policies include NGOs, educational centers, producer organizations, trade associations, and local government agencies such as extension services. They also are market information systems, certification systems, regulatory mechanisms to make clear the rules of the game, and enforcement mechanisms - both public and private-to monitor and ensure compliance. These hardware and software aspects work best when there is transparency and interrelatedness in the systems. Such institutions provide consistency at the local level as well as market-oriented linkages to international technology and information. Without these frameworks, smaller 
producers and SMEs will find it difficult to adapt and to improve their capacity and to equitably participate in value chains and markets. 


\section{References}

Boselie, D. 2002. Business Case Description: TOPS Supply Chain Project, Thailand. KLICT International Agri Supply Chain Development Program. The Hague: Agri-Chain Competence Foundation.

Busch, Lawrence, and Carmen Bain. 2004. New! Improved? The Transformation of the Global Agrifood System. Rural Sociology 69 (3): 321-346.

Cato, J. C., and S. Subasinge. 2003. Case Study: The Shrimp Export Industry in Bangladesh. Focus 10, Brief 9 of 17, September 2003. Food Safety in Food Security and Food Trade. Washington, D.C., International Food Policy Research Institute.

Center for Science in the Public Interest. 2007. Cited in the Wall Street Journal article "Going Proactive on Food Safety." 15 October 2007.

COA. 1999. Fair Market or Market Failure? A Review of Australia's Retailing Sector. Report by the Joint Select Committee on the Retailing Sector. August. Canberra: Commonwealth of Australia.

Dardaine, Emilie. 2003. Building Partnerships, the Difficulties Encountered by Small Farmers to Meet the Requirements of the International Market. Text of speech at the third expert meeting on Socially and Environmentally Responsible Horticultural Production and Trade on 16 February 2003. Nürnberg, Germany. Online at: ftp://ftp.fao.org/paia/organicag/meet160203 4a.pdf

Fulponi, Linda. 2005. Private Voluntary Standards in the Food System: The Perspective of Major Food Retailers in OECD Countries. Food Policy, 31(1), pages 1-13.

Gereffi, G. 1994. The Organization of Buyer-Driven Global Commodity Chains: How U. S. Retailers Shape Overseas Production Networks. Commodity Chains and Global Capitalism. G. Gereffi and M. Korzeniewicz. London: Praeger.

Gereffi, G. 2001. "Shifting Governance Structures in Global Commodity Chains, with Special Reference to the Internet." American Behavioral Scientist 44(10: 1616-1637).

Gereffi, G., and M. Korzeniewicz, Eds. 1994. Commodity Chains and Global Capitalism. London: Praeger.

Grievink, J. 2003. The Changing Face of the Global Food Industry. Presentation at the OECD Conference on Changing Dimensions of the Food Economy: Exploring the Policy Issues, The Hague, 6 February 2003 OECD.

Giovannucci, Daniele. 2006. Salient Trends in Organic Standards: the Opportunities and Challenges for Developing Countries. In: "Standards and Trade: Challenges and Opportunities for Developing Country Agro-Food Trade" course. Washington, DC: World Bank Institute-USAID, Trade Standards Working Group. Available online at: http://www.dgiovannucci.net/docs/Salient_Trends_in_Organic_StandardsOpportunities_for_Developing_Countries.pdf

Giovannucci, Daniele, and Morton Satin. 2006 (republished from 2001). Food Quality Issues: Understanding HACCP and other quality management techniques. VirtualPRO, the on-line journal of Industrial Processes Engineering at: www.revistavirtualpro.com Also at: http://lnweb18.worldbank.org/essd/essd.nsf/a235c63e6d22927585256866007098 83/37343b58a4cf229c852568ae0012cbff/\$FILE/ATTAAQ33/food_quality_issues.pdf 
Giovannucci, Daniele, and Stefano Ponte. 2005. The Collective Formulation and Effectiveness of Public \& Private Sustainability Standards: In special issue of Food Policy Journal, "Private Agrifood Standards: Implications for Food Policy and the Agrifood Systems."

Giovannucci, Daniele. 2005. Organic Agriculture and Poverty Reduction in Asia. IFAD: Rome. Available online

at: http://www.dgiovannucci.net/docs/Evaluation_of_Organics_in_Asia_IFADGiovannucci\%20.pdf

Giovannucci, Daniele P., Patricia Aust Sterns, Michael Eustrom, and Hyde Haantuba. 2001. The Impact of Improved Grades and Standards For Agricultural Products in Zambia. Phase One Assessment and Recommendations for United States Agency for International Development (RCSA): Johannesburg.

Giovannucci, Daniele, and Thomas Reardon. 2000. Understanding Grades And Standards and how to apply them. (D. Giovannucci, Ed.). World Bank: Washington, D.C. Available online at: http://web.worldbank.org/WBSITE/EXTERNAL/TOPICS/EXTARD/0,,contentMDK:204 41034 pagePK:210058 piPK:210062 theSitePK:336682,00.html

Hazell, P. 2004. Last chance for the small farm? IFPRI Forum. IFPRI: Washington, D.C.

Hu, D., T. Reardon, S. Rozelle, P. Timmer, and H. Wang. 2004. The Emergence of Supermarkets with Chinese Characteristics: Challenges and Opportunities for China's Agricultural Development. Development Policy Review, 22 (4): 557-86.

Jaffee, Steven, and Spencer Henson. 2004. Standards and Agro-Food Exports from Developing

Countries: Rebalancing the Debate. World Bank Policy Research Working Paper 3348: Washington, D.C.

Kaplinsky, R., and M. Morris. 2001. A Handbook for Value Chain Research. Brighton, United Kingdom, Institute of Development Studies, University of Sussex.

Lu, Wencong. 2005. Trade and Environment Dimensions of the Food and Food-Processing Industries: A Case Study from China. In United Nations Economic and Social Commission For Asia and the Pacific regional workshop on "Trade and Environment Dimensions in the Food and Food Processing Industries in the Asia and the Pacific," 16-18 October 2006. Bangkok, Thailand.

MMWBP. 2005. Issues of Contracts: Applications to Value Chains in Viet Nam. Making Markets Work Better for the Poor Project Briefing No. 6. Asian Development Bank and the Department for International Development (UK). Hanoi, Viet Nam.

MMWBP. 2007. Linking Farmers to Markets through Contract Farming. Chapter 5. Markets and Development Bulletin. Making Markets Work Better for the Poor Project, Asian Development Bank and the Department for International Development (UK), Hanoi, Viet Nam.

Moustier, Paule, Dao The Anh, Hoang Bang An, Vu Trong Binh, Muriel Figuié, Nguyen Thi Tan Loc, and Phan Thi Giac Tam. 2005. The Participation of the Poor in Supermarkets and other Distribution Value Chains. Making Markets Work Better for 
the Poor Discussion paper No. 11, Asian Development Bank and Department for International Development (UK). Hanoi, Viet Nam.

Natawidjaja, Ronnie, S. Trisna Insan Noor, Tomy Perdana, Elly Rasmikayati, Sjaiful Bachri, Thomas Reardon, Ricardo Hernàndez. 2006. The Impact of the Rise of Supermarkets on Horticulture Markets and Farmers in Indonesia. Center for Agricultural Social Economics Research and Development: Bogor.

Nguyen, Do Anh Tuan, Trung Kien Nguyen, Cong Thang Tran, Le Trong, and Karl Rich. 2004. The Participation of the Poor in Agricultural Value Chains: A Case Study of Cassava. Making Markets Work Better for the Poor Project, Asian Development Bank and Department for International Development (UK). Hanoi, Viet Nam.

Patrick, I. 2003. Contract Farming in Indonesia: Smallholders and Agribusiness Working Together. ACIAR Technical Reports No. 54. Canberra, Australian Centre for International Agricultural Research.

Poulton, C., P. Gibbon, B. Hanyani-Mlambo, J. Kydd, W. Maro, M. Nylandsted Larsen, A. Osorio, D. Tschirley, and B. Zulu. 2004. Competition and Coordination in Liberalized African Cotton Market Systems World Development 32 (3):519-536.

Purcell, Tim, and Karl Rich. 2002. Rice Value Chain Study: Cambodia. A Report Prepared for the World Bank. Phnom Penh, Cambodia, Agrifood Consulting International.

Purcell, Tim, and Ganesh Rauniyar. 2005. Cambodian Agrarian Structure Study. Prepared for the Ministry of Agriculture, Forestry and Fisheries, Royal Government of Cambodia, the World Bank, the Canadian International Development Agency (CIDA), and Gesellschaft für Technische Zusammenarbeit (GTZ). Phnom Penh: Agrifood Consulting International.

Purcell, Tim, and Rudy Van Gent. 2005. Synthesis Study on Options for Smallholder Commercialization. Project P091803 under the Zambia Smallholder Agricultural Commercialization Strategy. Lusaka, Zambia: Agrifood Consulting International for the Government of Zambia and the World Bank.

Reardon, T. 2005. Retail Companies as Integrators of Value Chains in Developing Countries: Diffusion, procurement system change, and trade and development effects. Deutsche Gessellschaft fur Technische Zusammenarbeit: Eischborn.

Reardon, Tim, and J. Berdegué. 2002a. "The Rapid Rise of Supermarkets in Latin America: Challenges and Opportunities for Development." Development Policy Review 20(4: 371-388).

Reardon, Tim, and J. Berdegué. 2002b. "Supermarkets and Agrifood systems: Latin American Challenges." Development Policy Review Theme Issue 20(4).

Reardon, Thomas, C. Peter Timmer, Christopher B. Barrett, and Julio Berdegué. 2003. "The Rise of Supermarkets in Africa, Asia, and Latin America." American Journal of Agricultural Economics 85: 1140-1146.

Setboonsarng, Sununtar. 2006. Organic Agriculture, Poverty Reduction, and the Millennium Development Goals. ADB Institute Discussion Paper No. 54. 
Sykuta, M., and J. Parcell. 2002. Contract Structure and Design in Identity Preserved Soybean Production. Contracting and Organizations Research Institute (CORI) Working Paper No. 2002-01, University of Missouri, Columbia: Columbia, MO, USA.

Tran, Cong Thang, Emma Samman, Karl Rich, Pham Quang Dieu, Nguyen Do Anh Tuan, Nguyen Van Thanh, and Dang Van Thu. 2004. The Participation of the Poor in Agricultural Value Chains: A Case Study of Tea. Making Markets Work Better for the Poor Project, Asian Development Bank and Department for International Development (UK): Hanoi.

Vander Stichele, M. S. van der Wal, and J. Oldenziel. 2006. Who reaps the fruit?: critical issues in the fresh fruit and vegetable chain. Centre for Research on Multinational Corporations (SOMO): Amsterdam.

Van Gelder, Jan W., Jan Joost Kessler, Wolfgang Richert, Jan Maarten Dros, Myrthe Haase, and Matthijs Schuring. 2006. Increasing the sustainability of EU and Dutch commodity trade through more effective policies. The Hague: The Netherlands Ministry of Housing, Spatial Planning and Environmental Management (VROM).

Vorley, B. 2003. Food, Inc.: Corporate Concentration from Farm to Consumer. London, UK: Food Group and International Institute for Environment and Development. 